\title{
LE PREMIER MINISTRE SUR LE SENTIER DE LA GUERRE OU LE CHIEN À DEUX QUEUES. LE LANGAGE NON CONVENTIONNEL DANS LE DISCOURS POLITIQUE (ANTI-)BELLIQUEUX HONGROIS
}

\section{INTRODUCTION.}

Dans ce travail, nous nous intéresserons au langage politique hongrois du milieu des années 2010, et plus particulièrement à la place de l'argot dans le discours politique belliqueux et, surtout, anti-belliqueux. Avant de commencer notre enquête, nous pensions que le langage du premier ministre hongrois Viktor Orbán pourrait être une source intéressante d' « argot de guerre », étant donné qu'il n'a pas peur d'appeler un chat un chat, et, surtout, que sa politique semble reposer en grande partie sur la nécessité d'avoir des ennemis. Les communistes, les Russes, les socialistes, les libéraux, les migrants ${ }^{1}$, les musulmans, les terroristes (confondus consciemment avec les précédents), Bruxelles (en tant que capitale de l'U.E.), le milliardaire américain d'origine hongroise George Soros ou l'Université qu'il a fondée, selon les époques et selon les besoins, sont tous devenus les cibles du gouvernement, les ennemis d'autrefois pouvant devenir des amis par le passage du temps ${ }^{2}$. L'important c'est d'avoir des ennemis, pour resserrer les liens et mobiliser les troupes ${ }^{3}$.

Ce n'est pas la peine d'insister ici, dans ce numéro de Linguistica consacré à l'argot de la guerre, sur le rapport étroit entre les phénomènes langagiers de type argotique et l'armée, la vie militaire et la guerre. Nous renvoyons néanmoins à l'analyse de l'argot de la guerre par une des figures majeures de l'argotologie française : Albert Dauzat (1956 : 49). Les liens entre la politique et les argots sont également documentés depuis longtemps : Partridge (1970 : 149) mentionne parmi les principales variétés du slang celui du parlement et de la vie politique.

* szabo.david@btk.elte.hu

1 En ce qui concerne l'utilisation consciente du terme hongrois migráns « migrant » à la place de l'équivalent de « réfugié », voir l'article de Körmendy (2017).

2 Citons le cas de la Russie de Poutine, ancienne ennemie devenue une des meilleures amies de la Hongrie orbanienne.

3 Pour la situation politique hongroise, voir par ex., l'article de Dávid Szabó dans l'Année Francophone Internationale 2016-2017 (http://www.agora-francophone.org/afi/afi-no25-2016-2017/article/ hongrie-par-david-szabo?id_mot=27, consulté le 21/06/2017). 


\section{ORBÁN ET L'IDÉE DE LA GUERRE}

Nous allons illustrer l'idéologie orbanienne de la nécessité de trouver un ennemi contre lequel on peut faire la guerre, par un extrait d'un discours prononcé par le premier ministre hongrois l'année dernière :

... ő megadta azt a mondatot, amiről nekem most itt igazából, azt kiindulópontul választva beszélnem kell. Nehémiást idézte: „Ne féljetek, harcoljatok!” De mit is jelent ez? Mert mi ellen kell harcolni? Ha nem tudjuk meghatározni, hogy mi ellen kell harcolni, akkor nem tudjuk meghatározni, hogy mi a harc jó formája, mi az, ami célszerú, és mi az, ami kontraproduktív, nem tudjuk kiválogatni az eszközöket. Ha nem tudjuk megmondani, mi ellen harcolunk, akkor nem tudjuk, hogy melyik a célravezető eszköz, és melyik az, amelyik inkább nekünk árt ${ }^{4}$.

Il suffit de lire cet extrait pour voir que l'idée de la nécessité de la lutte y apparaît avant la nécessité de bien choisir son ennemi.

Cette lutte « permanente » du gouvernement hongrois semble d'autant plus intéressante d'un point de vue linguistique qu'heureusement, il ne s'agit pas d'une vraie guerre, dans le sens physique et sanglant du terme, du moins à quelques exceptions près ${ }^{5}$. Cette guerre se matérialise plutôt sous la forme de brochures de propagande envoyées par la poste aux électeurs hongrois, d'affiches ${ }^{6}$ martelant, le long des routes, l'objet de la lutte, ou de nouvelles et articles publiés dans les médias pro-gouvernementaux.

La tabouisation consciente de certains termes fait partie de cette guerre par les mots qui devient ainsi une guerre des mots. Ancien libéral ${ }^{7}$ reconverti en politicien conservateur, Orbán - et la droite hongroise en général - utilise depuis longtemps les termes hongrois liberális « libéral » et balliberális « libéral de gauche ${ }^{8}$ » avec une nuance très péjorative, et les médias publics pro-gouvernementaux, dominants depuis quelques années, suivent son exemple. La stigmatisation de termes a priori neutres comme liberális peut conduire à leur tabouisation dans certaines situations voire dans certains milieux : un locuteur libéral ou de

4 « ... il [le pasteur protestant L. Tökés ; note du traducteur] a prononcé la phrase dont je dois parler ici en la choisissant comme point de départ. Il a cité Nehémie: „N'ayez pas peur, luttez !’Mais qu'est-ce que cela veut dire ? Contre quoi doit-on lutter ? Car si nous ne sommes pas capables de définir ce contre quoi nous devons lutter, nous ne pourrons pas choisir non plus la forme convenable de la lutte, ce qui est adapté et ce qui ne l'est pas, nous ne pourrons pas choisir les moyens. Si nous sommes incapables de préciser contre quoi nous luttons, nous ne savons pas non plus quels sont les moyens les plus adaptés et quels sont ceux qui nous nuisent. » (Discours prononcé à Tusnádfürdő [Băile Tuşnad, Roumanie] le 23/07/2016)(traduit par l'auteur). (24.hu. Consulté le 21 juin 2017 : http://24.hu/kozelet/2016/07/24/nem-hitt-a-fulenek-mar-el-is-olvashatja-orban-viktor-beszedet/).

5 Nous pensons notamment à l'accueil brutal réservé aux réfugiés aux frontières méridionales de la Hongrie.

6 Citons la campagne gouvernementale contre la relocalisation des réfugiés qui faisait partie des préparatifs d'un référendum.

7 Précisons que dans le contexte hongrois, les connotations politiques et sociales de « libéral» sont tout aussi importantes que les aspects économiques.

8 Le terme fait allusion avant tout à l'ancienne coalition entre les socialistes et les libéraux. 
gauche peut avoir du mal à utiliser le terme dans un milieu conservateur, même dans un contexte non politique. Alors qu'il veut dire « favorable aux libertés individuelles », son interlocuteur risque de comprendre « permissif » voire « contraire aux intérêts du pays »?.

Contre toute attente, les premières enquêtes, conduites sur Internet et dans les médias pro-gouvernementaux, n'ont pas été concluantes. Aussi intéressant que soit ce corpus d'un point de vue linguistique, les discours d'Orbán et la propagande pro-gouvernementale semblent - dans l'état actuel des recherches ${ }^{10}$ - très pauvres en éléments argotiques et non conventionnels.

Nous pourrions certainement tirer des conclusions fort intéressantes de cette constatation, mais nous avons préféré nous tourner vers les réactions populaires au comportement belliqueux d'Orbán et son gouvernement ${ }^{11}$. Cette réorientation de notre analyse paraissait d'autant plus prometteuse que des recherches menées dans d'autres pays sur des corpus comparables ont démontré les aspects créatifs, ludiques et expressifs du langage que certains appellent anti-sloganique (Woch 2015 : 107-108, Bastian 2017 : 22-27).

\section{LE PARTI DU CHIEN À DEUX QUEUES}

Dans la campagne qui précédait le référendum du 2 octobre 2016 sur la relocalisation des réfugiés, le seul parti à s'être réellement opposé à Orbán et le mécanisme gouvernemental était un petit parti parodique tout jeune, le parti du chien à deux queues. Ce parti luttant avec les armes de l'humour, issu d'une association créée en 2006, a été fondé en $2014^{12}$.

La citation suivante illustre bien l'idéologie du parti, c'est-à-dire l'approche satirique et humoristique, ainsi que sa prise de position pacifiste, anti-belliqueuse :

Az alábbi videókban összeszedjük azokat a recepteket amikből főzni szoktunk. Azokat a hasznos információkat tartalmazzák, amiből Te magad is kifözheted a saját kutyapártos- vagy kutyapártfüggetlen forradalmadat!

A szakácskönyv-metaforát azért használjuk, mert meggyőződésünk, hogy a jobb atmoszféra érzéki, esztétikai kérdés, mint az ízek és a hangok - de ha harciasabbak lennénk, akkor nevezhetnénk fegyvertárnak is, ha meg mókusok lennénk, akkor mogyorónak ${ }^{13}$.

9 Cf. Szabó (2017) «Tabous linguistiques de la vie politique hongroise ». Acta Romanica Lodziensis, Folia Litteraria Romanica 12, 165.

10 Nous devons insister sur l'aspect préliminaire de ces recherches.

11 «Envoyons un message à Bruxelles, pour qu'ils comprennent aussi », disaient les affiches du gouvernement protestant contre la relocalisation des réfugiés. Sur certaines affiches, des mains inconnues ont ajouté : « Dans les écoles, il n’y a pas de papier toilette aux W.-C. »

12 Pour plus d'informations, voir http://ketfarkukutya.com/?page_id=1233 (consulté le 21/06/2017).

13 «Les vidéos suivantes illustrent les recettes que nous avons l'habitude de préparer. Elles contiennent les informations utiles suivant lesquelles tu peux préparer toi-même ta révolution avec ou sans le parti du chien à deux queues ! Nous employons cette métaphore de livre de recettes car nous sommes convaincus qu'une meilleure atmosphère, c'est une question de sens et d'esthétique, comme les goûts et les sons - mais si nous étions plus combatifs, nous pourrions parler d'arsenal, alors que si nous étions des écureuils, nous parlerions de noisettes. » (traduit par l'auteur)( http://ketfarkukutya.com/?p=1829. Consulté le 21/06/2017). 


\section{1. La campagne du parti du chien à deux queues.}

Comment un petit parti parodique qui s'autodéfinit comme pas très combatif fait-il la " guerre » contre les brochures, les affiches et les slogans du gouvernement ? A coup d'affiches anti-sloganiques, satiriques et absurdes. Aux affiches gouvernementales mettant la population en garde contre les migrants (« Le saviez-vous? A partir de la seule Libye, près d'un million de migrants veulent venir en Europe ${ }^{14}$. »), le parti parodique a opposé des affiches (certes bien moins nombreuses mais d'autant plus voyantes) disant « Le saviez-vous? Le Hongrois moyen voit plus d'ovnis que de migrants dans sa $v i^{15}$. » Le fait que les affiches gouvernementales étaient tellement nombreuses que certaines d'entre elles étaient à peine visibles, inspirait aux activistes (appelés passzivista, " passiviste ») l'anti-slogan suivant : " Le saviez-vous? Si vous mettez un texte trop long sur une affiche, personne n'aura le temps de le lire ${ }^{16}$. »

La dernière série d'affiches commandée par le gouvernement disait simplement « Ne kockáztassunk! Szavazzunk nemmel! » (Ne prenons pas de risques ! Votons contre $\left.!^{17}\right)$. Le parti du chien à deux queues a réagi par un jeu de mots absurde : « $\mathrm{Ne}$ kockáztassunk! Savazzunk menyéttel! » (Ne prenons pas de risques! Répandons de l'acide avec des belettes !). Jeu de mots qui reposait sur la proximité formelle des verbes hongrois szavaz « voter » et savaz « répandre de l'acide » et la proximité relative entre nem « non » et menyét « belette ». Sur d'autres « contre-affiches », le message du chien à deux queues était encore plus simple : « Hülye kérdésre hülye választ ! Szavazz érvénytelenül !» (A question stupide, réponse stupide ! Vote nul !).

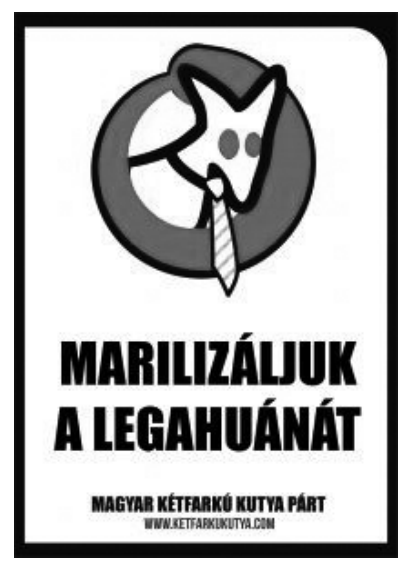

Figure 1. «Marilizáljuk a legahuánát !» (Légalisons la marijuana !) ${ }^{18}$

14 Tous les exemples en français ont été traduits par l'auteur. L'affiche originelle disait en hongrois : «Tudta ? Csak Líbiából közel egymillió bevándorló akar Európába jönni. »

15 En hongrois : « Tudta? Egy átlagos magyar több ufót lát élete során, mint bevándorlót. »

16 En hongrois: «Tudta? Ha túl hosszú szöveget ír egy plakátra, akkor senkinek sem lesz ideje elolvasni. »

17 Il s'agissait de dire non à la relocalisation des réfugiés voulue par l'U.E.

18 http://ketfarkukutya.com/?page_id=66. Consulté le 25/06/2017. 
Ajoutons encore qu'en dehors des affiches parodiant des affiches pro-gouvernementales de la campagne du référendum du 2 octobre 2017, le parti du chien à deux queues avait également des affiches moins occasionnelles qui semblaient se moquer de la démagogie politique en général («Vie éternelle. Bière gratuite. Baisse des impôts $\left.{ }^{19} »\right)$ ou proposaient des objectifs politiques alternatifs («Légalisons la marijuana! »). Cette dernière proposition est particulièrement intéressante d'un point de vue linguistique : l'anti-slogan « Marilizáljuk a legahuánát ! » est un néologisme obtenu par un procédé morphologique (métathèse) à partir du hongrois usuel « Legalizáljuk a marihuánát ! ». (fig. 1)

\section{2. La réaction du gouvernement hongrois}

En conséquence de l'anti-campagne du parti du chien à deux queues, le gouvernement s'est trouvé dans une situation embarrassante. D'une part, il est difficile de lutter contre l'humour, d'autre part, le parti du chien s'était positionné en dehors du clivage traditionnel entre gauche et droite, donc, la communication gouvernementale habituelle ne semblait pas avoir prise sur eux. Le gouvernement a apparemment opté pour la solution d'ignorer ce nouvel ennemi. En tout cas, les médias publics et pro-gouvernementaux, particulièrement actifs dans la campagne contre la relocalisation des réfugiés, ne parlaient pratiquement pas de l'anti-campagne du parti du chien. D'où le message suivant sur le site de ce dernier :

Nem akarok ezen nagyon pörögni ${ }^{20}$, csak gondoltam érdekeségképpen (sic) megemlítem, mégis csak a ti pénzetekből van a közszolgálati televízió. Egyelöre a koreai médiafogyasztók többen tudnak rólunk, mint akik csak m1-et néznek.:)

Szóval kezd vicces lenne (sic), hogy az m1-en nem lehet rólunk beszélni, itt van pár külföldi cikk/videó, majd még bővítjük a listát. Amiben segíthetnétek is, ha láttok rólunk külföldi anyagot, akkor plíz küldjétek a linket a ketfarkukutya@gmail.com-ra ${ }^{21}$ !

Outre quelques fautes d'orthographe caractéristiques du langage d'Internet (érdekességképpen megemlitem « il est intéressant de signaler » avec un seul-s, lenne à la place de lenni « être »), ce texte contient quelques éléments d'argot commun : pörög « s'en faire » (par glissement sémantique, du hongrois usuel « tournoyer $\rightarrow$ hongrois argotique « s'activer », suivi de vmin « sur qc »); plíz « s'il vous plaît», de l'anglais please, même sens.

\subsection{Les résultats de l'anti-campagne du parti du chien à deux queues}

La campagne parodique du parti du chien a porté ses fruits. Si le référendum du 2 octobre 2016 n'a pas pu être validé avec une participation nettement en-dessous du

19 En hongrois : (« Örök élet. Ingyen sör. Adócsökkentés ».

20 Les termes non conventionnels sont en gras.

21 «Je sais qu'il faut pas s'en faire, mais je peux pas m'empêcher de noter que la télé publique, c'est vous qui la payez. Pour le moment, le public coréen nous connaît mieux que ceux qui ne regardent que $\mathrm{m} 1(-)$ En tout cas je commence à trouver ça drôle qu'on peut pas parler de nous sur $\mathrm{m} 1$, voici quelques articles/vidéos étrangers, la liste sera mise à jour progressivement. Pour nous aider, si vous voyez des documents étrangers sur nous, envoyez svp le lien à ketfarkukutya@ gmail.com. » (Traduit par l'auteur. http://ketfarkukutya.com/?p=1802. Consulté le 22/06/2017.) 
seuil des $50 \%$, et si les votes nuls et blancs n'avaient jamais été aussi nombreux, c'était en partie dû à l'intervention critique, satirique et souvent absurde de ce nouveau parti.

Les bulletins de vote nuls, photographiés dans l'isoloir ou sortis du bureau de vote, témoignent souvent de la créativité langagière des sympathisants du parti du chien à deux queues ${ }^{22}$. Sur les photos, on voit par exemple un bulletin non orthodoxe : unortodox szavazólap = « bulletin de vote non orthodoxe », d'une épithète utilisée par le gouvernement pour qualifier sa politique économique (surtout celle du président de la Banque de Hongrie) s'écartant des principales tendances européennes (fig. 2) ; sur un autre, nous trouvons la phrase Mongyon le !, variante de Mondjon le ! «Qu'il démissionne! » (souvent entendu dans les manifestations), écrite avec une orthographe non conventionnelle. Aux deux options, oui et non, l'électeur a ajouté une troisième : talán « peut-être ». Un troisième bulletin, en dehors d'une tête d'extraterrestre, contient l'expression argotique anglaise reality sucks, « la réalité, ça craint. »

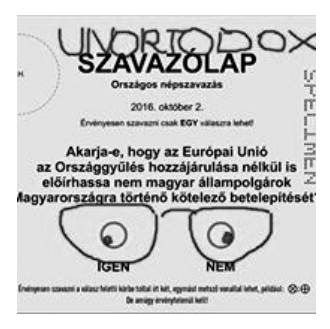

Figure 2. Bulletin de vote nul « non orthodoxe $»^{23}$.

\title{
3.4. Le chien à deux queues fait ses comptes
}

Alors que le gouvernement hongrois a utilisé une somme faramineuse pour sa campagne $^{24}$, l'anti-campagne proportionnellement bien plus efficace du parti du chien n'a coûté qu'environ 110 mille euros. Vous trouverez ci-dessous les comptes du parti parodique, intéressants non seulement d'un point de vue financier :

\author{
Bevételek : \\ Emberektől kapott adományok: $34530099 \mathrm{Ft}$ \\ Utalások gyíkemberektől: $734532411 \mathrm{Ft}$ \\ Itt a részletes lista, a gyíkembereket természetesen titkosítottuk. \\ Kiadások :
}

22 Pour des photos de bulletins de vote nuls voir par ex., index.hu: http://index.hu/belfold/2016/10/02/ kvotareferendum_ervenytelen_szavazatok/. Ou la page Facebook du parti du chien à deux queues : https://www.facebook.com/pg/justanotherwordpresspage/photos/?ref=page_internal. Consultés le 24/06/2017.

23 https://www.facebook.com/pg/justanotherwordpresspage/photos/?ref=page_internal. Consulté le $25 / 06 / 2017$.

24 Selon certaines estimations la campagne du gouvernement hongrois a coûté plus cher que la campagne autour du Brexit au Royaume-Uni. 
Embereknél elköltött pénz : $35126432 \mathrm{Ft}$

Gyíkember-közeli alapítványoknak átjátszott pénz : $734532411 \mathrm{Ft}$

$\underline{\text { Részletes kiadási lista gyíkemberek nélkül. }}$

Számlák beszkennelve itt. A gyíkemberes számlákat a Szíriuszon tekinthetik meg minden nap 173 és 174 óra közt.

A különbséget hozzáraktuk pártpénzből, úgyhogy megint csórók vagyunk.

Ebben értelemszerüen nincs benne a rengeteg ember rengeten (sic) önkéntes melója. Azzal együtt (ha fizettünk volna nekik) kb dupla lett volna a kiadás, próbáljuk még azt is kiszámolni, és közzétesszük. Még majd kiszámoljuk azt is, hogy mennyibe került volna a kampányunk ha a Kormány csinálja, ők ugye kétszer annyiért szoktak óriásplakátokat bérelni, mint mi, plusz ugye a habonyi juttatások ${ }^{25}$.

A part les hommes-lézards, une légende urbaine connue en France aussi, ces comptes mentionnent également le système de l'étoile Sirius lequel, selon une légende urbaine plus particulièrement hongroise, aurait des liens avec les origines de Magyars... Nous y trouvons aussi quelques éléments d'argot commun : csóró « fauché », adjectif d'origine tsigane, et meló « boulot», substantif d'origine yiddish.

\section{EN GUISE DE CONCLUSION}

Contrairement au langage belliqueux du gouvernement hongrois et plus particulièrement à celui de la campagne contre la relocalisation des réfugiés conduite en été et automne 2016, très pauvres en éléments non conventionnels, le langage du parti hongrois du chien à deux queues et de sa campagne anti-belliqueuse est très créatif et riche en néologismes. Les textes du parti parodique recèlent également des éléments argotiques, surtout des termes d'argot commun, sortis depuis longtemps de leurs micro-argots d'origine, qui, outre leur fonction ludique évidente, n'ont plus de fonction

25 «Recettes :

Dons d'êtres humains : $34530099 \mathrm{Ft}$

Virements de la part d'hommes-lézards: $734532411 \mathrm{Ft}$

Voici la liste détaillée, les noms des hommes-lézards ont naturellement été cryptés.

Dépenses :

Argent dépensé sur des êtres humains : $35126432 \mathrm{Ft}$

Argent passé à des fondations liées à des hommes-lézards : $734532411 \mathrm{Ft}$

Liste détaillée sans hommes-lézards.

Factures scannées ici. Les factures des hommes-lézards peuvent être consultées sur Sirius chaque jour entre 173 et 174 heures.

La différence a été complétée grâce au budget du parti, donc nous sommes redevenus fauchés.

Ces comptes ne comprennent évidemment pas le taff bénévole de tout un tas de gens. Avec ça, si nous les avions payés, nos dépenses auraient augmenté à peu près par deux, nous essaierons de faire des calculs, pour les publier ici. Nous calculerons aussi combien notre campagne aurait coûté si elle avait été faite par le gouvernement, comme on le sait, ils ont l'habitude de louer des placards deux fois plus chers que nous, sans oublier l'argent versé à Habony [conseiller du premier ministre ; note du traducteur]. » (traduit par l'auteur, http://ketfarkukutya.com/?m=201610, consulté le 24/06/2017. 
cryptique ou identitaire proprement dite, mais qui, avec les jeux de mots et les néologismes, arrivent tout de même à créer des liens entre des gens paisibles et pacifistes qui aiment bien l'humour et n'apprécient pas le langage trop sérieux de ceux qui ne pensent qu'à faire la guerre.

\section{Bibliographie}

\section{Corpus}

http://ketfarkukutya.com/. Consulté le 25/06/2017.

https://www.facebook.com/justanotherwordpresspage/. Consulté le 25/06/2017.

\section{Références bibliographiques}

BASTIAN, Sabine (2017) « Le discours de l'immigration : langue de bois vs jargons et néo-argots. » In : Montserrat Planelles Iváñez/Jean-Pierre Goudaillier (éds.), Argot et crises. Frankfurt am Main : Peter Lang Edition, 13-30.

DAUZAT, Albert ([1924 ] 1956) Les argots. Caractères-évolution-influence. Paris : Delagrave.

KÖRMENDY, Mariann (2016) « Migrer, émigrer, immigrer ou le sens du mouvement. » Revue d'Etudes Françaises 21, 85-89.

PARTRIDGE, Eric ([1933] 1970) Slang To-day and Yesterday. London: Routledge and Kegan Paul.

SZABÓ, Dávid (2017) « Tabous linguistiques de la vie politique hongroise. » Acta Romanica Lodziensis, Folia Litteraria Romanica 12, 161-170.

WOCH, Agnieszka (2015) «L'expressivité et l'identité dans le langage anti-sloganique : le cas de l'anti-publicité politique sur Internet. » Acta Romanica Lodziensis, Folia Litteraria Romanica 10, 101-108.

\section{Résumé \\ LE PREMIER MINISTRE SUR LE SENTIER DE LA GUERRE OU LE CHIEN À DEUX QUEUES. LE LANGAGE NON CONVENTIONNEL DANS LE DISCOURS POLITIQUE (ANTI-)BELLIQUEUX HONGROIS}

Ce travail analyse les aspects argotiques et non conventionnels du langage politique hongrois contemporain, et plus particulièrement le langage anti-belliqueux d'un petit parti parodique tout récent, le parti du chien à deux queues. Alors que le discours habituellement belliqueux du gouvernement hongrois était, lors de la campagne contre la relocalisation des réfugiés, en 2016, pauvre en éléments argotiques ou en néologismes, la campagne du parti parodique était, d'un point de vue linguistique aussi, bien plus créative et non conventionnelle que celle du gouvernement. Notre analyse est fondée en majeure partie sur un corpus recueilli sur Internet en 2016-17.

Mots-clés : argot politique, langage politique, langage anti-sloganique, néologie 


\title{
Abstract \\ THE PRIME MINISTER ON THE TRAIL OF WAR OR THE DOG \\ WITH TWO TAILS. NON-CONVENTIONAL LANGUAGE IN HUNGARIAN ANTI-WAR POLITICAL DISCOURSE
}

In this paper I analyse Hungarian political slang, or slang as it is used in Hungarian politics, especially as it appears in the pro-refugee campaign of a recently created mock party, the Hungarian Two-tailed Dog Party. While the Hungarian government, during its campaign against the relocation of refugees, used very few slang or colloquial terms, the language of the Two-tailed Dog Party is rich in slang words and neologisms. The analysis is mostly based on data gathered on the Internet in 2016-17.

Keywords: political slang, political language, anti-sloganic language, neology

\author{
Povzetek \\ PRENIER NA VOJNEM POHODU OZIROMA PES Z DVEMA REPOMA. \\ NEKONVENCIONALNI JEZIK V (PROTI)VOJNEM MADŽARSKEM \\ POLITIČNEM DISKURZU
}

Članek analizira argojevske in nekonvencionalne prvine v sodobnem madžarskem političnem jeziku, še posebej pa protivojni govor manjše parodične stranke, ki se je nedavno pojavila: »stranke psa z dvema repoma«. Če je bil govor madžarske vlade, ko je šlo za begunsko krizo v letu 2016, zelo borben in je vseboval malo argojevskih elementov in neologizmov, je bila kampanja parodične stranke tudi z jezikoslovnega vidika bolj inovativna in manj konvencionalna kot vladna. Naša analiza se v največji meri opira na korpus, pridobljen na internetu v letih 2016-2017.

Ključne besede: politični argo, politični jezik, jezik proti sloganom, neologija 